\title{
CERTAIN ASPECTS OF CITY FINANCING AND CITY PLANNING
}

\author{
BY ANDREW WRIGHT CRAWFORD ${ }^{2}$ \\ Philadelphia
}

$\mathrm{T}^{\mathrm{n}}$

$\mathrm{HE}$ genius of modern life is to do justice; and yet there is hardly a municipal bond issue by which injustice is not done. Bonds are issued to pay for the construction of things that will not last for the life of the bonds. Thirty-year or fifty-year bonds for street paving, which will have to be completely replaced in ten, or, at most, fifteen years, are constantly authorized. The taxpayers for the last fifteen years of the life of the bonds, in cases where they are to run for thirty years, and the taxpayers of the last thirty-five years, where the bonds are to run for fifteen years, are thereby compelled to pay interest and sinking fund charges for a thing which they cannot by any possibility enjoy.

This injustice is not confined to things that are completely obliterated before the end of the life of the bonds. The more common, though less glaring, manifestations of it are in the inadequate conception or execution of municipal work to be paid for through bond issues. All kinds of public undertakings are conceived, either with reference only to the needs of the present or of the immediate future,- - of not more than the next decade. Fifty-year bonds are issued to pay for improvements which will be quite inadequate fifty years hence, and which will have to be greatly enlarged in capacity long before they are completely paid for through the amortization of the bonds. While a part of the original construction may be useful in the enlargement, frequently all of it is useless and the cost of its removal makes the total cost greater than if unoccupied ground were available. Thus underplanning entails avoidable expense and is, therefore, extravagance.

Failure or inability to foresee or want of courage to act in accordance with true vision is responsible for this waste in American municipal expenditures.

It is submitted that no issue of municipal bonds should be sought by city officials, unless the thing to be constructed by those bonds will last as long as the bonds themselves, and, further, unless it will be measurably

${ }^{1}$ An address delivered at the Sixth National Conference on City Planning.

${ }^{2} \mathrm{Mr}$. Crawford, who is a member of the Philadelphia bar, is the secretary of the art jury of Philadelphia and of the city parks association. He is a member of the executive committee of the National conference on city planning and of the National housing association.-Editor. 
adequate for the needs of the community at the end of the life of the bonds as well as at its beginning.

The administration that is not consciously and conscientiously endeavoring to foresee and measurably to provide for the needs of the future should be confined in its expenditures to the income of the present.

I have referred to thirty- and fifty-year bonds. As it is becoming the fashion to authorize the issue of fifty-year bonds I shall hereafter refer to fifty-year bonds, noting now that what is said in regard to them is generally applicable to thirty-year bonds also, with an obvious reduction in proportion or in emphasis.

American cities double in population in twenty-five years. A city of 100,000 to-day will be 200,000 in 1939 . This means that by 1964 it will have doubled again and be 400,000 , a population four times that of to-day. This obvious result is not so obvious to the official who is thinking only of the present. I recently saw a computation of the future population of a city made by a newly appointed secretary of a city planning commission, in which he took the total growth of the last fifty years and assumed that the total growth of the next fifty years would be exactly the same. He assumed that the absolute figures would be the same, not the percentage. "Dealing in futures" has heretofore been a little known art in municipal operations. The figures given above show that in fifty years the average American city will quadruple in population. The logical conclusion follows, that if the thing now constructed by the proceeds of the sale of fifty-year bonds, is to be commensurate with the needs of the people who, in the latter years of the bonds' life, will be making use of that thing, and also paying interest and sinking fund charges thereon, the needs of a population approximately four times the present one must be considered if for no other reason than to avoid the doing of palpable injustice.

The efficient life of the thing constructed by the proceeds of municipal bonds should measure their term, that efficiency being measured by adequacy of service to the community, and city planning is indispensable to determine that length of efficient life of a municipally constructed thing. Hence the issuance of city bonds calls for city planning as a prerequisite.

I have purposely qualified the duty of to-day in this regard as being that of providing "measurably" for the needs of fifty years hence. To provide absolutely for such needs would compel us in 1914 to provide, and to pay proportionately for, a thing four times greater in capacity than required by us who have approximately but one-fourth the financial resources of 1964 . That would be injustice to ourselves. How shall we adjust this difficulty? How shall we equitably provide payment for things needed now in a measure, which will hereafter be needed in the same, or a greater, or, conceivably, a smaller measure? This question will find 
an answer to some degree in a differentiation among the things constructed by the proceeds of municipal bonds-a differentiation of which I give examples, not a catalogue.

In the case of outlying parks, we, who secure them, should pay the minimum. Fifty years hence these parks, now suburban, and now somewhat of a joyous luxury, will be indispensable to their urban neighborhoods. We should be able to issue bonds for such parks with a very small sinking-fund charge to-day, graded up to a very large charge fifty years hence-more: we should make park bonds run seventy-five or one hundred years and make their present amortization charges negligible.

The term of paving bonds should be in the neighborhood of fifteen years and the immediate amortization charge should be very heavythe charge fourteen or fifteen years hence very light. We who have the pavement at its finest should pay the highest toll.

Stone and concrete bridges are expected to last for seventy-five years. Bonds issued to provide the money for them should run as long. It is more difficult to determine whether their amortization charges should be graded up or down, or kept at one figure throughout. In the case of centrally located bridges, perhaps the last course would be advisable. In the case of bridges in suburban territories, their future greater usefulness justifies a heavier future sinking-fund charge.

The system of main sewers may deserve a diminishing amortization charge-of main streets, an increasing one. Public buildings probably deserve a diminishing charge throughout-though possibly the summit of their serviceableness is neither at the end nor at the beginning of the life of the bonds issued from them, but at some period during that life-proably nearer its beginning than its end; the deterioration of the physical building must be considared and deterioration begins at once.

On the other hand bonds issued to provide funds for the acquisition of the real estate upon which public buildings are to be erected, clearly deserve an increasing amortization charge throughout. The division for taxation purposes, of land from improvements thereon, will show how markedly the former often increases in value while the latter decrease. Each other city improvement should be considered likewise.

It is true that some of these suggestions would require changes in state constitutional provisions before they could be carried out. But if city planning should contemplate a minimum of fifty years for physical results, a minimum argued for hereafter, a delay of four or five years in order to secure constitutional changes is not of paramount importance. Moreover, while the inquiry as to present legal capacities is obviously an important part of a city survey, city planning must necessarily contemplate changes in organic law from decade to decade; it is a part of city planning to plan future laws as well as future structures. Constitutional provisions and acts of legislatures will change during fifty years 
anyway; there will be much gain if they are planned to meet city planning requirements pari passu.

The desirability of providing for graded amortization charges, though a constitutional change is involved, has been recognized. One example, of which, doubtless, there are others, may be found in a proposed amendment to the constitution of Pennsylvania, which passed the last legislature, but which will have to pass the next one and then be ratified by the electors. The amendment is to enable the city of Philadelphia to borrow three per cent over the existing limitations of seven per cent "for the construction and improvement of subways, tunnels, railways, elevated railways and other transit facilities; for the construction and improvement of wharves and docks, and for the reclamation of land to be used in the construction of wharves and docks, owned or to be owned by the city," and it provides, in part: "In incurring indebtedness for any one or more of said purposes, . . . the city of Philadelphia may issue its obligations maturing not later than fifty years from the date thereof, with provision for a sinking fund sufficient to retire said obligation at maturity, the payments to such sinking fund to be in equal or graded annual installments."

It may be noted in passing that this amendment follows the admirable precedent, already established in other states, of providing that in regard to these two classes of improvements, the borrowing capacity of a city at any time is to be ascertained by excluding from the calculation a credit where the work resulting from any previous expenditure of loan moneys is self-supporting.

Obviously, all of these methods of municipal financing and each of these differentiations among its objects require the careful study, forethought and prevision that are of the essence of city planning; they necessitate city planning, if they are to be more than guesses.

It will not have escaped you that any consideration of municipal bonds in connection with city planning establishes the minimum for the time that should be contemplated in city planning. It does not necessarily establish the maximum. But the minimum usually is in practice the maximum. In Pennsylvania, just before the enactment of the minimum wage law, its opponents sought the support of a manufacturer who was known to pay the lowest of low wages, and they asked him: "Do you believe in the minimum wage?" To which he replied: "Sure I do, I pay it!"

If the needs of the population at the end of the life of bonds, fifty years hence, must be considered as a mere matter of justice, obviously, our city planning must contemplate fifty years as its minimum; if in practice that does become also the maximum, I am not satisfied that any harm will result. Think of the inventions or improvements in inventions made during the last fifty years, especially those affecting communication,the telegraph, the telephone, the electric car, the motor car, the motor 
truck and the German dirigibles-to suggest a few-and I think you will agree with me that it is enough to attempt to forecast the needs of an urban population four times that of to-day.

A striking example of changes in the problems we have to deal with in city planning was brought out by a report at the meeting of the third International Road Congress at Ghent in 1913, which S. D. Adshead thus abstracts:

A census of traffic taken on a fine Sunday afternoon in the spring of the present year on a certain secondary arterial road leading out of London, showed that the average number of vehicles passing in one hour was: Motor buses 50, motor cars 300, motor bicycles 50; bicycles 100 , and horse-drawn vehicles 15. A fair presentation of the Saturday and Sunday crowd.

This particular section of the road chosen for observation was straight for about one third of a mile and had no cross roads. Deviations in its alignment at either end prevented excessive speed; but a computation showed that motor buses attained an average pace of fourteen miles per hour and motor cars twenty-five. It was a narrow road, being only twenty-six feet in width between the curbs, but it has a fine surface of wood block which has been recently laid.

Ten years ago it was paved with macadam and at the same time of day and on the same day in the year it would have been traversed by a continuous procession of cyclists, a few horse buses and other horse traffic of a lighter kind. Twenty years ago it was a carriage drive, a route for agricultural wagons and light tradesmen's carts, and it also provided a. means of access to the metropolis for those possessed of a horse.

The changes in condition of usage which have overtaken this secondary arterial road leading out of London apply with equal force to roads leading out of every town of importance in Europe and America.

As in the period of twenty-five years the average city doubles in population, and as the terms of administration of city officials are becoming generally four years, it follows that each administration will see a growth of the city approximating the proportion of four years to twenty-five years, twelve per cent to fifteen per cent. In some cases it will be less; in others more. But each administration must prepare for a growth of upwards of fifteen per cent that will oecur in the city's size during its term. This will be reflected chiefly on the city's perimeter but it will react also on the city generally, on the central portion especially and on the subcentres intermediately. The more intensive future use of the portions of the city already built requires our present more extensive preparation. Each administration should at least take care of the additions to the physical requirements of public service that will become needed during its term of office.

Municipal work may be divided into two grand divisions; one, the maintenance and operation of the existing municipal plant; the other, the planning and construction of additions thereto, and the replanning and reconstruction of portions of it. In respect to its plant, the commonly 
accepted analogy that a city and its citizens resemble a corporation and its stockholders fails to be true, and hence is misleading. An ordinary corporation can stop its growth, if its directors or stockholders determine that it shall do so. The growth of the municipal plant cannot be stopped.

The maintenance and operation of the existing plant, to which the attention of municipal officials has been so largely given heretofore, is unquestionably of immediate and pressing importance, but the expert skill and knowledge required for planning for the growth of the city that will. take place each year, each ten years and each fifty years is of a higher order than that required for maintenance and operation. Just as it takes a higher degree of expert knowledge and skill to plan and build a house than to make repairs to it afterwards, so it requires a better understanding of the problem, a more expert solution and more efficient construction work to plan and build the additions necessary for the future growth of the city, than to maintain and operate what has already been constructed. It used to be said that a carpenter could build a house and he did not need an architect to tell him how to do it; many cities have been built, and some are still being built by similarly self-satisfied municipal carpenters. It ultimately costs more money to correct a house badly planned or skimped in its construction, than to build it right in the first place, and it costs the city vastly more to reconstruct itself, where it has been planned on wrong, mean or short-sighted lines, than to construct it well on broad lines, in the first place. And the direct money cost is not the only cost. John Burns well said "mean streets make mean people"; and we may paraphrase the remark by saying that mean city planning makes a mean city, and a mean city makes mean citizens.

City planning, which has to do with all the elements that make up the physical city, involves not only planning but decision. The study of the one and the exercise of the other are as important duties as any to which a municipal administration can give its attention. During the course of any one day, or any one year, or any five years, this may not appear to be true; if the city were sure to cease to exist with the expiration. of any such period, it would not be true; but, considering the entire future life of the city, not the dead past nor the fleeting present, but the far reaches of the future, it is true.

Fortunately the resources of a city increase with its needs. Failure to appreciate the fact that the annual income from taxation will be larger and the annual addition to the borrowing capacity of the city will be greater with each succeeding year, is the reason why the larger and larger plans prepared annually appear to be exceeding the capacity of the city. Our present plans, if they are to be adequate when materialized in the future, must be correspondingly extensive, based on an: understanding not only of what the needs of the future will be, but of 
what the financial ability of that future will be. It is difficult to persuade people that any plan to be carried out in twenty-five years, for which the present capacity of the city is sufficient, is to be regarded because of that fact alone, as probably inadequate, as probably providing for a result at the end of those twenty-five years that will not be commensurate with the then existing needs; the sufficiency of the present capacity of the city to finance the plan throws the burden of proof on its proponents to show the enduring sufficiency of the plan itself.

Certain of the more direct financial considerations that have to do with city planning have been discussed at these conferences. The method of paying for various kinds of improvement, through assessments on the property benefited, has been emphasized as an admirable American method, where the sole question is how to finance a municipal improvement. The method of excess condemnation, where, in addition to providing, in whole or in part, for the cost, it is desired to exercise some control of abutting property, as by the regulation of occupation; the recasting of lot lines, the determination of lot and building widths and depths, the determination of minimum, maximum and proportionate heights of buildings, the regulation of the relation between buildings on adjoining lots, the prohibition of blind walls-again a suggestive list, not a catalogue-has been urged as a European method, desirable, and, if these ends are to be obtained, necessary for adoption here. Considerations of expediency will determine which method is the more available in individual cases. Generally, in undeveloped sections, assessment for benefits is the better method, while in developed sections, excess condemnation is preferable.

It should be borne in mind that where the power of excess condemnation is used, any loss as well as any gain will be the city's, whereas in the case of assessments for benefits, the loss, if loss there be, will be the property owner's. Greater justice is thus often secured by excess condemnation.

Frequently, the combination of the two methods will be advantageous: to condemn immediately abutting property to a desirable lot depth and control its development by the creation of easements, will spread the resulting increase in values over a greater territory than if such abutting property were left uncontrolled in private hands. Immediately adjoining the excess area so condemned, there will be consequently an enlarged area subject to assessment for benefits. And, in addition to the returns, in the one case, from the sale of the excess property, and, in the other, from the special assessments, both areas will thereafter return annually a larger sum in taxes than before, thus taking care of proportionate interest and amortization charges on bonds that may have been issued to finance the work; or, if no such bonds were issued, thus securing a greater income for 
general municipal uses. The territory actually feeling an increment in value will exceed both areas.

In his admirable paper, entitled: "Paying the bills for city planning" delivered at the Boston conference on city planning, Nelson P. Lewis showed the justice of assessing the cost of rapid transit systems on the properties within their spheres of influence. A recent Philadelphia investigation confirmed the experience of New York City in this regard, by showing that a newly constructed rapid transit line so concentrated the normal general increase of the entire residential areas of the city within its own sphere of influence, as to cause an actual loss for six years in all the other residential areas combined, despite the erection of some 21,000 new houses in these other areas.

These experiences enable the exercise of municipal economy in another important respect.

Before a city proceeds to the undertaking of the construction of such lines, or before it permits their construction, the city should acquire the real estate it will need for all public purposes, whether for parks, playgrounds, parkways, streets, school-houses, police and fire stations, public libraries or what not, in the territory that will be tapped; otherwise, if it waits until it has enormously increased the value of such property and the amount, therefore, which it will have to pay, it will be guilty of rank folly. Elementary prudence dictates action before this unearned increment has actually accrued-unearned, that is, by the owners' money, but earned directly by the city's expenditure of money paid by the taxpayers, where the city constructs the system; and this increment begins long before completion of the new lines. City planning enables the exercise of similar far-sighted economy by present-day expenditure, in many respects other than the rapid transit system-parkways, other main thoroughfares, parks, river front improvements-in fact in the case of every public work where real estate, increased in value by its proximity to one public work, will be needed for another municipal service in the reasonably near future.

It will be observed that I am not here insisting upon the effect of the opening of parks, for instance, on adjacent land values. I am taking it for granted that there is no longer need of persuasion on this point; such testimony as the following: "During the sixteen years following the laying out of Central Park, the average increase in the assessed value of real estate in the other parts of the then city of New York was about 100 per cent while in the three wards then adjoining the new park, the increase was approximately 800 per cent"; - has been duplicated in greater or less degree so often, that we are now able to exercise morefar-sighted economy. Prompt expenditure is often the truest economy.

The broader financial aspects of city planning are frequently so general and illusory, so incapable of mathematical demonstration, that they 
have not been appreciated in America at anything like their financial worth to the community.

The manifestations of this monetary benefit fall naturally into two classes, namely, the benefit to citizens through the attraction and circulation of outside money, the magnetic cause of which is to be found in certain city-planning works; and the benefit to the city treasury in the addition to the city's annual income caused by higher assessments for taxation purposes of properties within the spheres of influence of such works. As an example of this lack of appreciation of opportunities, consider the great sum annually lost by American treatment-if utter neglect of glorious opportunities can be called "treatment" -of their municipal river banks. Think, first of course, of the beauty and attractiveness of European water-fronts, the Thames embankment with the Hotel Cecil and other high class properties crowding to its edge; the Seine; the hundreds of other European city rivers; and then, secondly and soberly, and in your counting-houses, compute the municipal money value of those works; in your calculations, assess the actual values of the properties fronting on the Seine, and compare them with what they would be if the Seine looked like the Chicago river; or the Schuylkill below Callowhill street in Philadelphia; or Jones' Falls in Baltimore; or the Anacostia Flats in Washington. Compare the actual values of the properties fronting on the Thames embankments with what they would have been if the river's banks looked the way they did at the beginning of Queen Victoria's reign. Then apply your tax rate to the differences and you will get an index to the primary loss caused by our American ignoring of the scenic value of river fronts. I am emphasizing the municipal value of riparian developments, mainly non-commercial, but there is a spirited, kaleidoscopic, fascinating scenic value and, hence, financial value, to the municipality in commerical water-fronts developed by masters who seek by-products. as well as direct results.

So far, of the loss to the city; now of the loss to the citizen.

Compute the value to the citizens of European cities of their river fronts. How much money would Parisians not get a chance at, if their river were as dilapidated, as uglified as ours are generally? The sums left by visitors to Paris each year are variously estimated from $\$ 50,000$-, 000 up to several times that sum. How much would Parisians lose if the Seine were not a gigantic work in sculpture?

There are not wanting indications that the financial value of a beautiful thing to the community as individuals as well as a municipal corporation is becoming more widely appreciated. In a recent decision concerning the Fairmount parkway, Judge Sulzberger, of the court of common pleas of Philadelphia County, said that such a feature "has an effect directly utilitarian. It increases the attractiveness of the city, induces strangers to visit it, and thus enlarges trade and commerce." 
It is a pleasure to note that we are beginning the redemption of our water fronts. Boston has begun it-true in a besitating, apologetic way, so as not to offend Beacon street!-still it has begun it. Toronto promises to do vastly better. The combination of a commercial and noncommercial development promises to set the precedent for American cities that has been needed so long. The early realization of its plans is, therefore, a matter of financial concern to practically every American city.

If beauty pays, how much does ugliness cost? Do we realize how dearly we are paying every year for our investment in rectangular, gridiron schemes of unattractiveness? City treasuries are losing money and citizens far more. Let us never forget, when discussing parkways, river embankments, park and playground systems, group plans and other physical developments, that there is another side to the picture, the side of the city without parkways, without river embankments, without parks and playgrounds, without civic centers, - the city crowded with overhead wires, with its sidewalks covered by overhanging, threatening signs, the curbs lined with ugly street fixtures. Which pays? Which costs? 